\title{
A CASE OF STYLO-HYOID OSSIFICATION
}

GEORGE P. LEONHART

From the Anatomical Laboratory, Western Reserve University, Cleveland, Ohio

TWO FIGURES

Stylohyoid ossification has received attention from time to time but such writings as are existent on the subject have most frequently been confined to the study of macerated specimens. There is thus still room for exact descriptions of instances which are discovered before the dissection has proceeded to any considerable extent. The present specimen was obtained in the dissecting-room of the Western Reserve University and was handed over to me for investigation by Mr. Wingate Todd. It occurred in the body of a white man fifty-five years of age, whose death was occasioned by alcoholism. As but little dissection had previously been done on the specimen, this has been a favorable opportunity, not only to describe the bony structures, but also to discuss the relation of the anomaly to the soft parts in the immediate neighborhood.

Enquiry into the clinical history of the individual did not elicit any symptoms referable to the condition, and definitely negatived any disability in speech or swallowing.

Dissection revealed a complete bilateral chain of ossicles representing the second or hyoid arch. This is shown in the accompanying radiogram. The 'prolongement hyoïdien' formed a stout irregular mass which projected some $13 \mathrm{~mm}$. from the temporal bone. This was succeeded by a bar of bone, ovoid in cross-section. On the left side there was little to indicate that this was composed of two fused elements. On the right side, however, the bar displayed a thickening which reached a maximum $22 \mathrm{~mm}$. from its upper extremity, and probably represented the original site of fusion. 


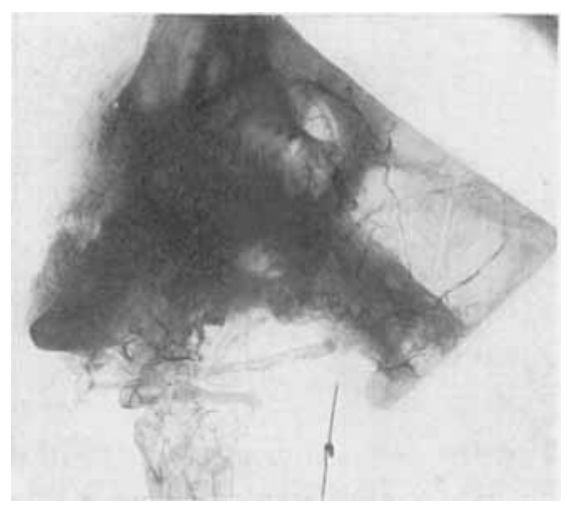

1

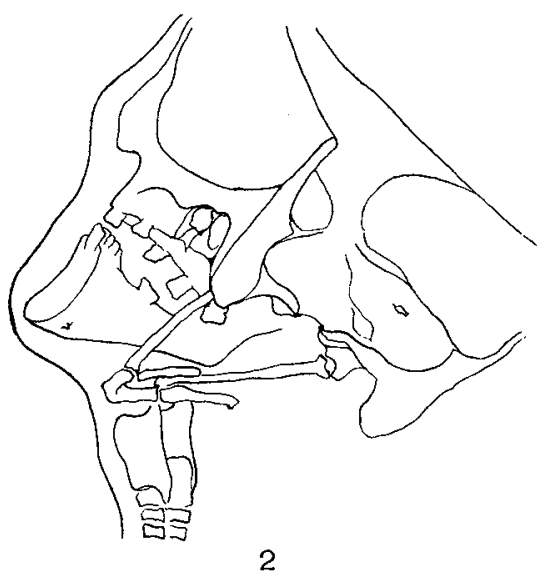

Fig. 1 Radiogram of head of man fifty-five years of age. One-fourth natural size. The soft parts are still in position, but the occiput, vertebral column and left half of the mandible have been removed to show more clearly the position of the ossified stylo-hyoid ligaments. The pointer indicates the articulation between the tympano-hyal and stylo-hyal elements on the right side. A small backwardly directed projection from the proximal extremity of the stylo-hyal is apparent. The left stylo-hyoid ossification is not in focus; it can be seen, however, as a dark shadow passing upward and backward to the interval between the molar teeth seen on the radiogram. The body of the hyoid and the greater cornua on the right side are clearly shown.

Fig. '? Key to radiogram. One-fourth natural size. In order more clearly to display the stylo-hyoid chain, the vertebral column, occiput and left half of the mandible were removed. The radiogram was then taken obliquely from behind. The right side of the hyoid apparatus is arranged in focus; the left side appears as a dark shadow. 
On each side, the bar of bone was succeeded by a lesser horn which was fused with the hyoid bone at the junction of the body with the greater cornu, this latter having not yet become ossified in one piece with the hyoid body. The measurements of the ovoid bar were the following:

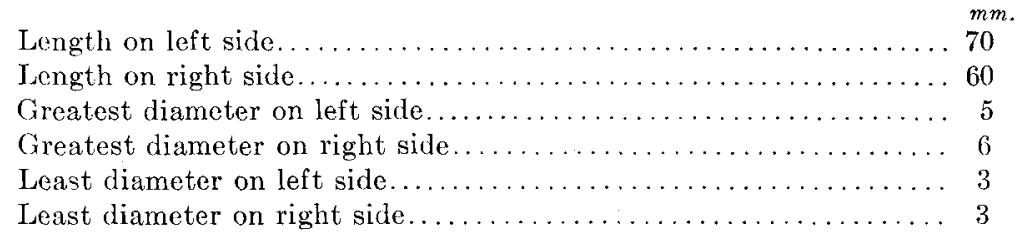

The lesser cornua were mere projections of cartilage, not differentiated from that which united the body with the greater cornua.

There being some confusion over the nomenclature of the various bony elements it may be well to define exactly what is meant by the terms used. Poirier (1) adopts the following names for the four elements represented: (1) The tympano-hyal for what has above been indicated as the 'prolongement hyoïdien;' (2) The stylo-hyal; and (3) The cerato-hyal for the proximal and distal parts respectively, of the bar of bone just described. The ceratohyal is usually represented in homo by the stylohyoid ligament. (4) The hypo-hyal corresponds to the lesser cornu.

This form of nomenclature was followed by Dwight in his recent paper on the subject (2) and is retained in this article. A different definition of terms is given by Keith (3).

Pseudo-articulations were present on both sides uniting tympano-hyal with the proximal end, and the hypo-hyal with the distal end of the long bar. The joints consisted of white fibrocartilage with no defined joint cavity. On the other hand, the tympano-hyal on both sides was fused to the rest of the temporal bone; there was but bare indication that the long bar consisted of stylo-hyal and cerato-hyal elements; and there was no joint between the hypo-hyal cartilage and the hyoid itself on either side. Thus all the elements were ossified with the exception of the hypohyals. The greater cornua displayed no terminal nodules of cartilage at their free posterior extremities. 
The body of the hyoid did not display the 'curved bar' referred to by Parsons as indicating the separate constitution of this bone by the 2nd and 3rd arches (4), but exhibited a median vascular foramen which may be a suggestion of the original double origin of the body. No representative of the glosso-hyal was present.

The upper extremity of the stylo-hyal on both sides presented a slight backwardly projecting process distantly reminiscent of, though probably not homologous with, the similar process on the ungulate stylo-hyal (5). The proximal ends of the stylo-hyals were $73 \mathrm{~mm}$. apart. The breadth of the skull between the most prominent parts of the mastoid processes was $120 \mathrm{~mm}$. The distal extremities of the cerato-hyals were $30 \mathrm{~mm}$. apart; cf. Gruber's case (15).

These measurements are given to show that the processes in this case did not constrict the posterior nares as occurred in the second of Lücke's cases (6). The fused stylo-snd cerato-hyals projected downward and inward. On the left side the bar of bone formed an angle of 50 degrees downward and forward and 75 degrees downward and inward. On the right side these measurements were respectively 65 degrees and 60 degrees.

The question of ossification being normal or pathological, it would be profitless to enter. The bone formation resulted doubtless from extension of the normal ossific process of the hyoid apparatus, which in such cases, as in instances of 'cervical' ribs, probably takes place at a much earlier date than used to be suspected; (for a discussion of dates see Dwight's paper). The present case is similar to that recorded by Turner but his instance was unilateral ( 7 ).

The following observations on the myology seem to be warranted:

The origin of the stylo-hyoid was, on both sides, from the posterior aspect of adjacent ends of the tympano- and stylo-hyals, by tendinous fibers.

The stylo-pharyngeus displayed an origin by muscular fibers from the same situation as did the stylo-hyoid but from the inner aspect of the process. 
The stylo-glossus arose by tendinous fibers from the anterior aspect of the whole length of the stylo-hyal element. There was, naturally, no stylohyoid ligament present.

Muscles which were looked for, but of which no vestige was found, were the hyoideus latus and hyoideus transversus. It was thought that possibly some remnant of these muscles, so well marked in Ungulata, might be found in homo in such a case as the present.

The masto-styloideus of ungulates (8) was represented only by very dense fascia passing from the mastoid process to the tympano-hyal and adjacent extremity of the stylo-hyal on both sides of the body. It formed part of the fascial bed for the parotid gland. No fibers could be traced directly into either the stylo-hyoid or stylo-pharyngeus.

On the right side was an example of the deep stylo-hyoid of Sappey (9). It arose from midway along the posterior aspect of the stylo-hyal by tendinous fibers, gave place to a small fusiform belly, and terminated in a fibrous bundle inserted into the hypohyal. According to Macalister this muscle represents one of the muscular bands found in bony fishes (10); see also Gavarde's example quoted by Macalister (16). On the left side the deep stylo-hyoid muscle was not found.

The relation of the styloid process to the bloodvessels confirmed the description already given by Dwight. On palpation through the mouth, the elongated stylohyoid process could be felt on each side, immediately below and behind the tonsil. In the cadaver it produced a distinct, though but slightly elevated ridge where the base of the tongue formed the anterior boundary of the vallecula. Dissection showed it to lie on the outer aspect of the bucco-pharyngeal fascia and distant by $5 \mathrm{~mm}$. from the oral pharyngeal mucous membrane. Its disposition was therefore similar to that of the process recorded by Kyle in his case of fractured styloid (11).

There was no constriction of the posterior nares. It would seem from Kyle's case, as from the present one, that the ossified ligament may produce no symptoms. In Kyle's case temporary 
aphonia, a sensation of constriction in the throat when singing or speaking and loss of the singing voice resulted from fracture of the process.

How far complete ossification of the styloid process may be responsible, in certain cases, for clinical symptoms, is not yet clear. Richardson records an instance of bilateral long styloid with which occurred post-nasal catarrh, soreness in the tonsillar region, difficulty in swallowing and soreness of the neck after much use of the voice. Moreover, the symptoms were cured by removal of the process (12).

Bigelow's case of the 'clicking woman' mentioned by Dwight, may have been an instance of ossified stylo-hyoid ligament (13). I have not thought it necessary to dwell upon those instances and clinical complications already referred to in detail by Dwight (2).

The position of the process in relation to the tonsil may be variable according to the length and direction of the bone. In Richardson's case already mentioned, a shorter process than the one recorded here, lay just within the anterior tonsillar fold and parallel to its course.

It is well to be on one's guard against the possible presence of the subpharyngeal cartilage of Luschka when making a clinical diagnosis of elongated styloid process. This is emphasized by Wingrave who mentions that besides occurring in the lateral wall of the pharynx, somewhat below and behind the faucial tonsil, the cartilage may also be present in the tonsil itself and in the latter situation, will give resistance to the guillotine (14).

In conclusion, I would express my obligation to Prof. T. Wingate Todd for his help throughout the investigation and in the writing of this article. 


\section{SUMMARY}

1. Complete ossification of the stylohyoid ligament may occur without the production of any clinical symptoms.

2. Associated with the anomaly, muscular variations may be present.

3. A frequent site of such an ossification is below and behind the tonsil in the anterior part of the vallecula where it may be palpated clinically.

4. The situation may vary, especially when the ligament is not ossified throughout its length. In such a case it may lie in front of the tonsil.

5. Constriction of the posterior nares or oral pharynx does not occur unless the process is markedly deflected.

6. In making the clinical diagnosis of ossified stylohyoid ligament, the occasional presence of the sub-pharyngeal cartilage of Luschka must be remembered.

\section{REFERENCES}

(1) Polrier, P. 1911 Osteologie. Traite d'anatomie humaine. 2nd Edit., T. 1, p. 354 .

(2) Dwight, T. 1907 Stylo-hyoid ossification. Ann. of Surgery, vol. 46, p. 721.

(3) Keith, A. 1913 Human embryology and morphology. 3rd Ed., p. 227.

(4) Parsons, F. G. 1909 The topography and morphology of the human hyoid bone. Jour. Anat. and Physiol, vol. 43, p. 279.

(5) Sisson, S. 1910 Veterinary anatomy. P. 65.

(6) LückE. 1870 Practische Bedeutung des abnorm langen und verbogenen Processus styloides des Schläfenbeins. Arch. f. path. Anat. u. Physiol., Bd. 51, p. 140.

(7) Turner, Sir W. 1902 Hyoid apparatus in man, in which a separate epihyal bone was developed. Jour. Anat. and Physiol., vol. 36, p. 162.

(8) Windee, B. C. A., and PArson, F. G. 1901 The museles of the Ungulata. Part I, Proc. Zool. Soc., London, December, p. 667.

(9) SAPpey 1912 Quoted by Poirier in Myologie. Traite d'anatomie humaine. 3rd Edit., T. 2, fasc. 1, p. 239.

(10) Macalister, A. 1897 Quoted by A. F. LeDouble in Traite des variations du systeme musculaire de l'homme. T. 1, p. 125. 
(11) KYLE, J. J. 1909 Anatomy and diseases of the styloid epiphysis. Ann. Otol. Rhinol. and Laryngology, vol. 18, p. 132.

(12) Richardson, C. W. 1909 Elongated styloid process. Trans. Amer. Laryng. Assoc., p. 171.

(13) Bigelow, H. J. Quoted by Dwight; see reference 2.

(14) Wrngrave, W. 1900 Dislocation of the styloid process. Brit. Med. Jour., vol. 2, p. 1639.

(15) Gruber, W. 1870 Ueber enorm lange Processus stylcideus der Schläfenbeine. Arch.f. path. Anat. u. Physiol, Bd. 50, p. 232.

(16) Macalister, A. 1871 The varieties of the styloid muscles. Jour. Anat. and Physiol., vol. 5, p. 29. 